diferentes frentes de trabalho que nem sempre têm aderência às propostas de mudanças. A busca do crescimento e do aperfeiçoamento profissional do enfermeiro é uma realidade e tem se dado de forma aleatória, na tentativa de se inserir no processo. O envolvimento e o desempenho dos enfermeiros nas atividades de educação para a saúde para pacientes, família e comunidade, de forma inovadora, têm trazido valorização e realização profissional, sinalizando um dos caminho através do qual buscam inovar sua prática, conquistar espaços na equipe interdisciplinar e na instituição, para participar das mudanças. Verificamos, ainda, que, mesmo não tendo participado das discussões do projeto do novo do hospital e não conhecendo a filosofia das mudanças em curso no HU, os enfermeiros estão caminhando em direção ao alcance dos objetivos propostos pela instituição, mostrando-se abertos e, de certa forma, permeáveis às mudanças.

\title{
DA BANALIZAÇÃO DO SOFRIMENTO À SUA RESIGNIFICAÇÃO ÉTICA NA ORGANIZAÇÃO DO TRABALHO
}

Autora: Carmem Lúcia Colomé Beck Orientadora: Maria Tereza Leopardi

\begin{abstract}
RESUMO: Este estudo caracteriza-se como uma investigação da área humano-social, do tipo exploratório-descritiva, estruturada a partir de uma abordagem qualitativa. Foi realizado com vinte enfermeiras e 26 auxiliares de enfermagem de dois hospitais da cidade de Santa Maria - RS e em cinco unidades consideradas críticas, quais sejam: a unidade de terapia intensiva de adultos, o centro cirúrgico, o pronto-atendimento, a unidade e o ambulatório de hematooncologia. A triangulação foi usada na coleta de dados, incluindo a entrevista semi-estruturada, a observação nos três turnos de trabalho e o preenchimento de um formulário junto com os trabalhadores de enfermagem. O problema que suscitou a investigação foi a cerca dos efeitos que a organização do trabalho e os eventos situacionais provocam na vida dos trabalhadores e, como objetivos, a caracterização das unidades críticas, a identificação destes eventos vivenciados pelos trabalhadores e a repercussão no modo de enfrentamento do sofrimento, bem como as relações entre os eventos presentes na organização do trabalho e a produção do sofrimento, desconforto, desprazer dos trabalhadores da enfermagem. A tese que foi defendida é de que a organização do trabalhador, bem como os eventos situacionais específicos, decodificados ou não, vivenciados individual ou coletivamente, em unidades críticas, produzem efeitos sobre o modo de enfrentamento do sofrimento. Esses modos apresentaram-se através da utilização de mecanismo de defesa, como a negação e a sublimação do sofrimento ou a partir da banalização do sofrimento quando os trabalhadores fazem de conta que nada está acontecendo, ou como se os acontecimentos fossem esperados e não requeressem decisões. Outras estratégias defensivas foram mencionadas pelos trabalhadores para fazer frente ao sofrimento, tais com: esquecer a qualquer custo o sofrimento cotidiano; separar a vida social da vida do trabalho; vivenciar crises e adoecer, tendo em vista os sentimentos não conscientes; anular as emoções; utilizar "válvulas de escape" para aliviar a ansiedade, dentre outras. Nesta situação, é possivel afirmar que estes trabalhadores ainda estão negando suas crises decorrentes do sofrimento do trabalho. Entretanto, percebi que alguns deles já buscam novas fórmulas de se relacionarem com o seu trabalho e de enfrentar o sofrimento e, portanto, já se situam na fase chamada "aumento da tensão", segundo Taylor (1992). As novas formas de enfrentamento do sofrimento incluem possibilidades como o reconhecimento da existência do mesmo; a necessidade de aprender a conviver com ele e de compartilhar essas experiências com os colegas; a busca do significado dessas vivências para a sua vida e o desejo de alcançar o equilíbrio entre sofrer sem limites, negar ou banalizar o sofrimento. A enfermagem permanece desempenhando o papel social esperado, ou seja, realizando aquilo que esperam dela "a qualquer custo". Outro achado importante foi o estado de alerta permanente revelado pelos trabalhadores, o qual precisa ser investigado com mais profundidade e associado às doenças apresentadas por eles, decorrentes do desenvolvimento do seu trabalho.
\end{abstract}

\section{SOFRIMENTO NA PRÁXIS DA ENFERMAGEM: REAL OU DESLOCADO EM SEU SENTIDO?}

Autora: Rosa Maria Bracini Gonzales Orientadora: Maria Tereza Leopardi

RESUMO: Neste estudo, defendendo a tese de que o sofrimento no trabalho da enfermagem é superdimensionado, muitas vezes potencializado pelas cargas do cotidiano social do individuo em vida de relações, o que se configura num deslocamento de sentido, ou seja numa desarticulação entre sua origem completa e aquela evidenciada pelos trabalhadores. $O$ grupo que participou do estudo foi composto por vinte enfermeiros e vinte auxiliares de enfermagem que constituíram uma amostra desta população, na cidade de Santa Maria - RS. Nesta pesquisa qualitativa, utilizei a entrevista semi-estruturada, realizada antes e depois do turno de trabalho, como instrumento para coleta de dados. Os objetivos que guiaram o estudo foram: 
reconhecer situações antecedentes ao trabalho que possam gerar ou induzir ao deslocamento de sentido tanto do prazer como do sofrimento dos trabalhadores de enfermagem no seu processo de trabalho; estabelecer parâmetros para discriminação entre o sofrimento real e o deslocado em seu sentido, dentre aqueles descritos pelos trabalhadores de enfermagem; evidenciar as formas encontradas pelos trabalhadores de enfermagem na produção de deslocamento de sentido do prazer ou sofrimento no trabalho, contribuindo para o aprofundamento reflexivo da temática. A análise teve por base quatro matrizes construídas a partir dos mitos de Apolo, Prometeu, Dioniso e Narciso. O estudo evidenciou a afirmação contida na tese, embora a dificuldade encontrada pela não percepção das pessoas, que poucas vezes param para pensar em questão como esta. Mostrou, também, que o cotidiano destes trabalhadores é atribulado pelo ritmo intenso imposto pela necessidade de conciliar mais de um trabalho, pela corrida frenética na tentativa de não deixar nada para trás, para atender as exigências da educação dos filhos, da manutenção do relacionamento afetivo, para honrar os compromissos financeiros assumidos, entre tantas outras coisas, próprias da vida destes homens e mulheres que compõe o quadro de pessoal da enfermagem. Aponto para a necessidade de construção de uma práxis reflexiva, relativa ao sofrimento e ao prazer no trabalho da enfermagem que, acredito, configura-se como uma possibilidade concreta para a vivência destas sensações no trabalho e na vida, de modo geral, tirando as pessoas da inconsciência em relação aos seus próprios sentimentos e permitindo que se estabeleça uma relação mais objetiva entre o sofrimento da vida social e o sofrimento da vida social do trabalho.

\title{
ENFERMERA, TRABAJO Y RESISTENCIA: EL SIGNIFICADO DE LA ESPERANZA: EL CASO DEL CEARÁ, BRASIL
}

Autora: Silvia Maria Nòbrega-Therrien

Orientador: Mariano Fernández Enguita

RESUMO: Las contribuciones de investigaciones socio históricas que estudian el trabajo y los trabajadores pueden surgir a partir de los clásicos que abordan este aspecto socio histórico y que pasa por Max, Engels, Weber, hasta Hobsbawa, Braverman y Thompson, entre muchos otros, sobretodo sociólogos e historiadores. Las investigaciones sobre el trabajo y más especificamente las estrategias colectivas o individuales de defensas, resistencias desarralladas por los trabajadores, presentan grande intéres para la comprensión del tema en cuestión. La forma por la cual los trabajadores o escapan de la explotación y dominación, ofrece subsidios para estúdios comparativos, pues la dominación y explotatción en los trabajos ocurre en diferntes contextos y socio culturales. Estas formas como también los contextos, por acrescentar diferencias, , nuevas dimensiones.

\section{PRAZER E O SOFRIMENTO NO COTIDIANO DO ENFERMEIRO DE CENTRO CIRÚRGICO}

\author{
PRAZER E O SOFRIMENTO NO COTIDIANO DO ENFERMEIRO DE CENTRO CIRÚRGICO \\ PRAZER E O SOFRIMENTO NO COTIDIANO DO ENFERMEIRO DE CENTRO CIRÚRGICO
}

Autora: Mônica Krahl

Orientadora: Rosita Saupe

\begin{abstract}
RESUMO: Las contribuciones de investigaciones socio históricas que estudian el trabajo y los trabajadores pueden surgir a partir de los clásicos que abordan este aspecto socio histórico y que pasa por Max, Engels, Weber, hasta Hobsbawa, Braverman y Thompson, entre muchos otros, sobretodo sociólogos e historiadores. Las investigaciones sobre el trabajo y más especificamente las estrategias colectivas o individuales de defensas, resistencias desarralladas por los trabajadores, presentan grande intéres para la comprensión del tema en cuestión. La forma por la cual los trabajadores o escapan de la explotación y dominación, ofrece subsidios para estúdios comparativos, pues la dominación y explotatción en los trabajos ocurre en diferntes contextos y socio culturales. Estas formas como también los contextos, por acrescentar diferencias, también se diferencian. En Basil, surgió uma avalancha de trabajos en las áreas de sociología y psicología, así como en el campo de las ciencias sociales, como los de Brandão (1964), Leite-Lopes (1978), que tienen aportado contribuciones significativas para los análises sobre el trabajo y el trabajador uma vez que buscan compreender la resistência de estos en la lucha contra la dominación y exploración. Son estudios que tiene la fábrica como locus de investigación. En el área de la salud de los trabajadores, se destacan los estudios de Laurel (1983), Laurel y Noriega (1989), Carvalho (1988), Minayo (1986) y Seligmann-Silva (1994). Las investigaciones hechas en el área especifica de infermeria ya fueron citadas y se
\end{abstract}

